\title{
COST272: PACKET-ORIENTED SERVICE DELIVERY VIA SATELLITES
}

\author{
E. Ferro*, H. Cruickshank**, L. Franck*** \\ ${ }^{*}$ ISTI/CNR (Italy), ${ }^{* *}$ University of Surrey (United Kingdom), ${ }^{* * *}$ ENST/TéSA (France)
}

\begin{abstract}
This paper presents the activities performed in the European funded COST272 Action. COST272 brings together European researchers involved in satellite communications. The contribution starts with a presentation of the COST framework, then the COST 272 motivation and activities are covered
\end{abstract}

Key words: Satellite communications, European research, COST project

\section{THE COST FRAMEWORK}

Founded in 1971, COST is an initiative by the European Commission (EC). The objective of COST is to co-ordinate nationally funded research at a European level ${ }^{1}$ in order to ensure that Europe holds a strong position in the fields of scientific and technical research. As such, COST stands for COoperation in the field of Science and Technology. Actions implemented in the COST framework are further categorised in domains, among these the Telecommunications domain, which COST272 naturally relates to.

There are about 200 COST Actions currently running, among these 20 in the Telecommunications Domain (see Table 1). Actions have an average duration of three to four years and are finalised through the delivery of a final report. Yearly reports also enable the monitoring of the Actions.

\footnotetext{
${ }^{1} 34$ states are now members of COST, widening the European scope of the framework
} 
COST is specific in the way that it provides by no means funding to conduct research. Rather, funding is allocated in order to make it possible for researchers to convene and exchange views about a given theme (satellite communications, in the case of COST272). The scope of each Action is described in a Memorandum of Understanding (MoU), submitted and approved by the European Commission. In order to submit a candidate MoU, at least 5 countries (among the participating countries) must sign an MoU, committing themselves in the participation of the Action.

\begin{tabular}{|l|l|}
\hline Action & Title \\
\hline COST270 & $\begin{array}{l}\text { Reliability of Optical Components and Devices in } \\
\text { Communications Networks and Systems }\end{array}$ \\
\hline COST271 & $\begin{array}{l}\text { Effects of the Upper Atmosphere on Terrestrial } \\
\text { and Earth-space Communications }\end{array}$ \\
\hline COST272 & Packet-Oriented Service Delivery via Satellites \\
\hline COST273 & Towards Mobile Broadband Multimedia Networks \\
\hline COST274 & Relational Structures as Knowledge Instruments \\
\hline COST275 & $\begin{array}{l}\text { Biometrics-Based Recognition of People over the } \\
\text { Internet }\end{array}$ \\
\hline COST276 & $\begin{array}{l}\text { Information and Knowledge Management for } \\
\text { Integrated Media Communication Systems }\end{array}$ \\
\hline COST277 & Non-linear Speech Processing \\
\hline COST278 & $\begin{array}{l}\text { Spoken Language Interaction in } \\
\text { Telecommunication }\end{array}$ \\
\hline COST279 & $\begin{array}{l}\text { Analysis and Design of Advanced Multiservice } \\
\text { Networks Supporting Mobility, Multimedia and } \\
\text { Internetworking }\end{array}$ \\
\hline COST280 & $\begin{array}{l}\text { Potential Health Implications from Mobile } \\
\text { Communication Systems }\end{array}$ \\
\hline COST282 & $\begin{array}{l}\text { Knowledge Exploration in Science and } \\
\text { Technology }\end{array}$ \\
\hline COST283 & $\begin{array}{l}\text { Computational and Information Infrastructure in } \\
\text { the Astronomical DataGrid }\end{array}$ \\
\hline COST284 & $\begin{array}{l}\text { Innovative Antennas for Emerging Terrestrial and } \\
\text { Space-Based Applications }\end{array}$ \\
\hline COST285 & $\begin{array}{l}\text { Modelling and Simulation Tools for Research in } \\
\text { Emerging Multiservice Telecommunications }\end{array}$ \\
\hline COST288 & $\begin{array}{l}\text { Electromagnetic Compatibility (EMC) in Diffused } \\
\text { Communication Systems }\end{array}$ \\
\hline Gesture Controlled Audio Systems \\
\hline Nanoscale and ultrafast photonics \\
Communications
\end{tabular}

Table 1: Actions currently running in Telecommunications, Information science and Technology 
A COST Action is driven by a Management Committee comprising up to two delegates from each signatory country. The Management Committee meets at least three times a year. For the sake of efficiency, an Action is often organised in Working Groups. Depending on the Action size and the allocated budget, meetings dedicated to the Working Group activities may also be held. Apart from meetings, the Action budget (50,000 Euros a year on the average) gives also provision for the organisation of Short Term Scientific Missions (STSMs). These missions make it possible for researchers to organise short stays in other institutions participating in the Action. STSMs act as a catalyst for the starting up of more permanent collaborations among institutions. Additionally, COST Actions are natural preludes to consortia formed as the result of EC issued calls for proposals.

In that respect, the European Commission has unveiled in mid 2002 some aspects related to the 6th Framework Programme (FP6). Two new tools are introduced in order to support the FP6: Networks of Excellence (NoE) and Integrated Projects (IP). It is interesting to note that NoEs are large scale COST Actions, in line with the concept of providing means to support research coordination while not funding the actual research effort. This way of proceeding credits a widespread feeling among the research community that theme-driven research activities are preferable better than goal-driven research, at least when non-competitive research is addressed.

\section{THE COST272 ACTION}

COST272 started in June 2001. Most of its participants came from two previous Actions: COST252 (Evolution of Satellite Personal Communications from 2nd to Future Generation Systems), and COST253 (Service Efficient Network Interconnection Via Satellites), ended in 2000. Table 2 summarises the Action data.

The main objectives of the action are to contribute to the identification of key requirements, analysis, performance comparison, architectural design and protocol specification of future packet-oriented satellite communication systems, with a clear focus on Internet-type system concepts, applications and protocols/techniques on the various layers. 


\begin{tabular}{|l|l|}
\hline Action Data \\
\hline Title & Packet-Oriented Service Delivery via Satellites \\
\hline Started in & June 2001 \\
\hline Ending in & June 2005 \\
\hline Chaired by & Dr Erina Ferro \\
\hline $\begin{array}{l}\text { Number of } \\
\text { meetings }\end{array}$ & Seven Management Committee Meetings \\
\hline Web site & lttp://www.tesa.prd.fr/cost272 \\
\hline Participants \\
\hline Belgium & Brussels University \\
\hline Croatia & University of Zagreb \\
\hline France & $\begin{array}{l}\text { French Space Agency (CNES), } \\
\text { Telecommunications for Space and Aeronautics } \\
\text { (TeSA), Telecom Paris (ENST) }\end{array}$ \\
\hline Germany & $\begin{array}{l}\text { German Aerospace Centre (DLR), Fraunhofer } \\
\text { Institute }\end{array}$ \\
\hline Greece & Aristotle University of Thessaloniki \\
\hline Italy & $\begin{array}{l}\text { Italian National Consortium for } \\
\text { Telecommunications (CNIT), National Council } \\
\text { for Research (CNR), Telecom Italia Lab }\end{array}$ \\
\hline $\begin{array}{l}\text { Telenor } \\
\text { Kingdom }\end{array}$ & \begin{tabular}{l} 
Kosice University \\
\hline Norway
\end{tabular} \\
\hline Slovakia & $\begin{array}{l}\text { University Carlos III of Madrid, University of } \\
\text { Slovenia }\end{array}$ \\
\hline Spain & \\
\hline
\end{tabular}

Table 2 : COST272 Action data

Satellite communications are currently not keeping pace with the development witnessed in terrestrial networks, however in an all-IP environment they could easily facilitate early deployment of the service to many users currently out of the reach of communication services. Deployment of such an all-IP environment in the satellite segment, however, requires the examination/study of suitability of the existing protocols and algorithms, and the implementation of the required modifications/adaptations, or even the development of more efficient algorithms that take into account the peculiarities of the satellite systems. Additionally, satellite communications are expected to play an important role in such competitive environment, driven by some recent technological advances which enabled: (i) the implementation of efficient inter-satellite links for the traffic interconnection in the satellite segment; (ii) onboard processing capabilities, aiming to improve dynamic resource utilisation and flexibility; and (iii) multiple spot beam coverage to optimise bandwidth efficiency. Based on these advances, broadband satellite networks will 
represent an attractive solution to provide two-way connectivity direct to the end user and to furnish new services such as high-speed Internet access and private network solutions. Furthermore, satellite networks are best suited to satisfy the increasing demand for the broadcast and multicast type of services with additional advantage of providing global accessibility.

These reasons are the strongest motive for the Action participants. In order to cope with the wide scope of the problem, the Action is subdivided in three Working Groups as shown in Figure 1.

After three years of activity, the Action has produced about 65 documents, covering subjects ranging from coding to security for multicast communications. The Action participants also promoted an Expression of Interest (called OSMOSISNET) as a reaction to an EC request in the scope of the FP6 preparation. Most of COST272 participants are also active in a Network of Excellence called SatNEx started in January 2004.

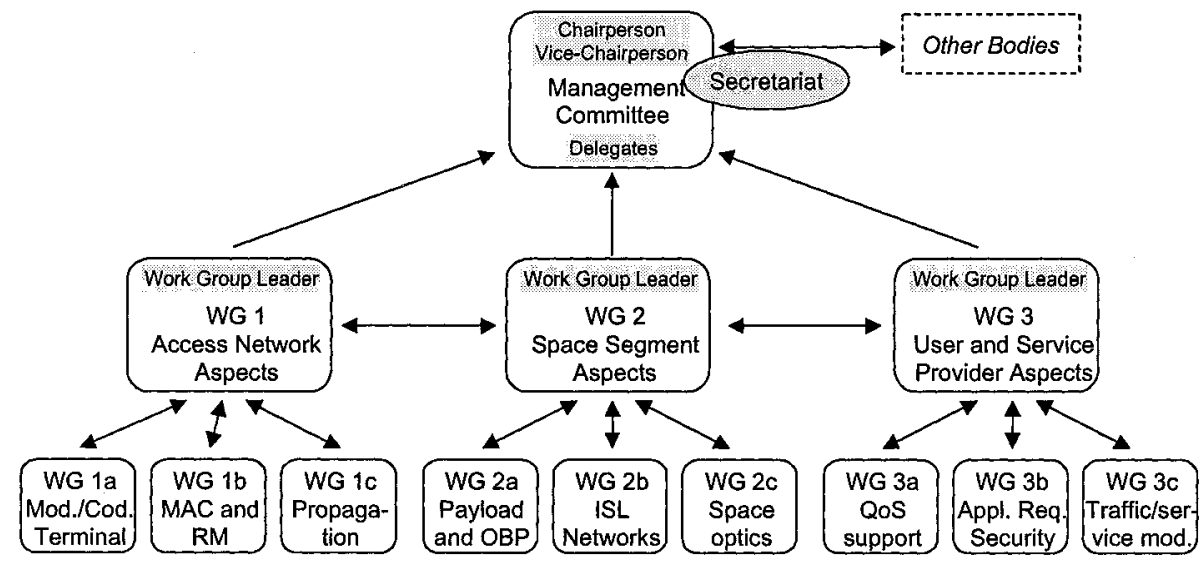

Figure 1: COST272 organizational structure

Additionally, more pragmatic issues are also addressed: since the Management Committee meets only three times a year, an alternate way to communicate was investigated, in order to set up virtual meeting sessions in between the MCM real meetings. For this purpose an experimental framework has been set up during 2002. Two participants (CNIT ${ }^{2}$ in Italy and $\mathrm{CNES}^{3}$ in France) had already multimedia transport realities in their own

2 Consorzio Nazionale Interuniversitario per le Telecomunicazioni (Italian National Consortium for Telecommunications).

${ }^{3}$ Centre National d'Etudes Spatiales 
countries: in Italy, the Ka-band satellite networking infrastructure of CNIT, and in France the Ku-band Eutelsat Hot Bird satellite transponder used by CNES to provide DVB-S demonstrations. For this experiment, the Italian and the French parties both used a combination of terrestrial and satellite links.

On the Italian site, the satellite network comprises six active earth stations operating in the Ka-band (20-30 GHz) over the Italsat satellite. Each station is connected to a CNIT laboratory where a number of instruments, PCs and various network devices are available for traffic emulation and field trials of satellite data services. The CNIT laboratories are also interconnected with HDSL leased lines and to the Internet through routers and dedicated firewalls. Among other applications, a subset of MBONE multicast tools have been long in use over this network, especially to deliver some distance learning lectures, now also broadcast in France.

In France, CNES utilizes $\mathrm{PCNS}^{4}$, an experimental DVB-S European platform. At the moment, PCNS, located in Toulouse, uses a 2 Mbps space channel over Eutelsat's Hot Bird satellite. Toulouse uplink site has a high speed connectivity to the Internet $(2 \mathrm{Mbps}$ dedicated to multimedia applications), and some additional interfaces (ISDN, H.320 videoconferencing, PSTN, etc). TV programs (1 channel) and IP multicast services are provided and can share available satellite bandwidth. They stay in separate constrained DVB sub-channels (PIDs) and can simultaneously be active. The interconnection with the PCNS platform has been realized from the CNIT site in Naples, where an IP-IP tunnel, encapsulating multicast packets, has been opened toward Toulouse by using the "plain" Internet terrestrial network (Fig. 2).

After that the concept has proven to be workable over "point to point" long distance, it has been progressively be extended to other COST272 participants (Spain and United Kingdom). The experimental platform used VIC and RAT videoconferencing tools (Figure 3) developed during the MICE and MERCI European projects. During assessment phase, COST272 participants had opportunities to schedule virtual meetings (through the ground Internet) on a "rendez-vous" point hosted by CNES-Toulouse.

At the time being, this experiment has ended. The technology proved to be workable even in heterogeneous environments. However the major pitfall lied in the ease of installation and configuration of the required software. Security considerations at the various sites raised also concerns about the possibility to establish the required connections.

\footnotetext{
${ }^{4}$ Plate-forme de Communication Numérique par Satellite
} 


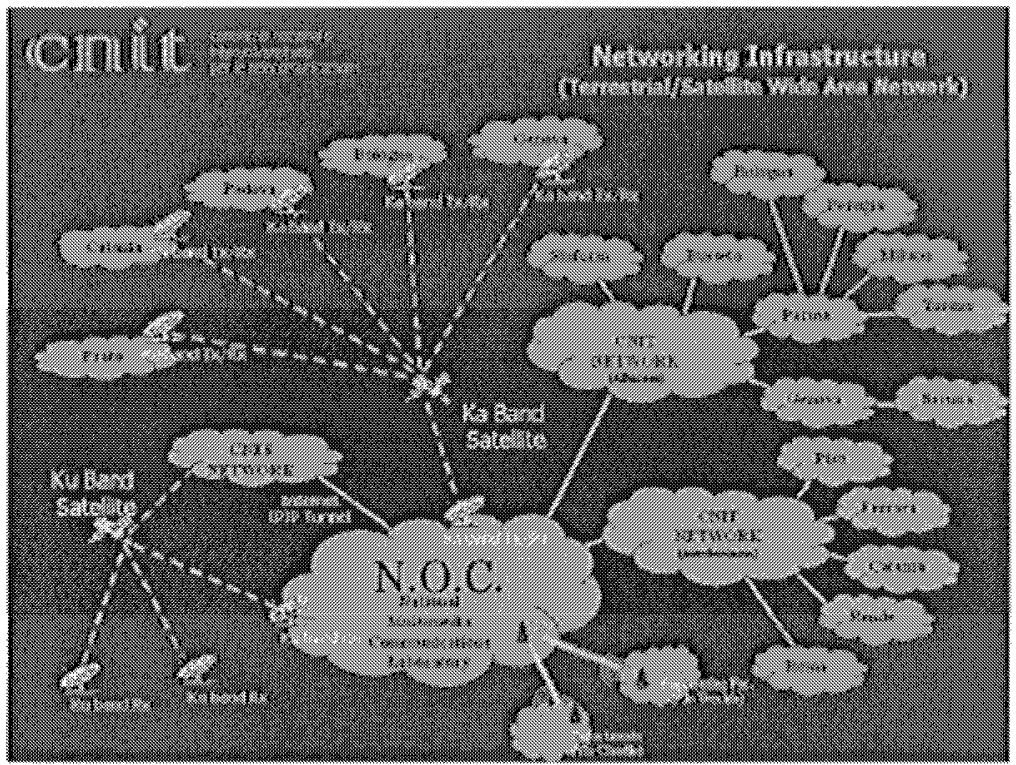

Figure 2 : The CNIT-CNES interconnection

\section{CONCLUSIONS}

The COST272 Action provides the opportunity for European researchers in the field of satellite communications to meet and co-ordinate their activities.

Current COST272 activities are distributed over two axes:

1. the integration within a European wide interactive network of satellite and terrestrial components, with the aim of validating user-friendly applications and demonstrating new services, thus enhancing the communication capabilities within the group at low expenses;

2. regular research activities around the Action themes. Expected research outcomes are:

- identification of technologies supporting IP over satellites and enabling new services and QoS guarantees;

- suitability to implement IP switching in the sky;

- adaptation of protocols and algorithms initially developed for the mixed mobile and fixed terrestrial networks, to make them suitable for the satellite segment; 
- development of new algorithms, designed ad-hoc for the satellite segment;

- suitability of using various optical technologies in the satellite space.

COST272 is also a core network for setting up industrial and academic consortia in view of elaborating proposals in response to calls for participation initiated by the European Commission.

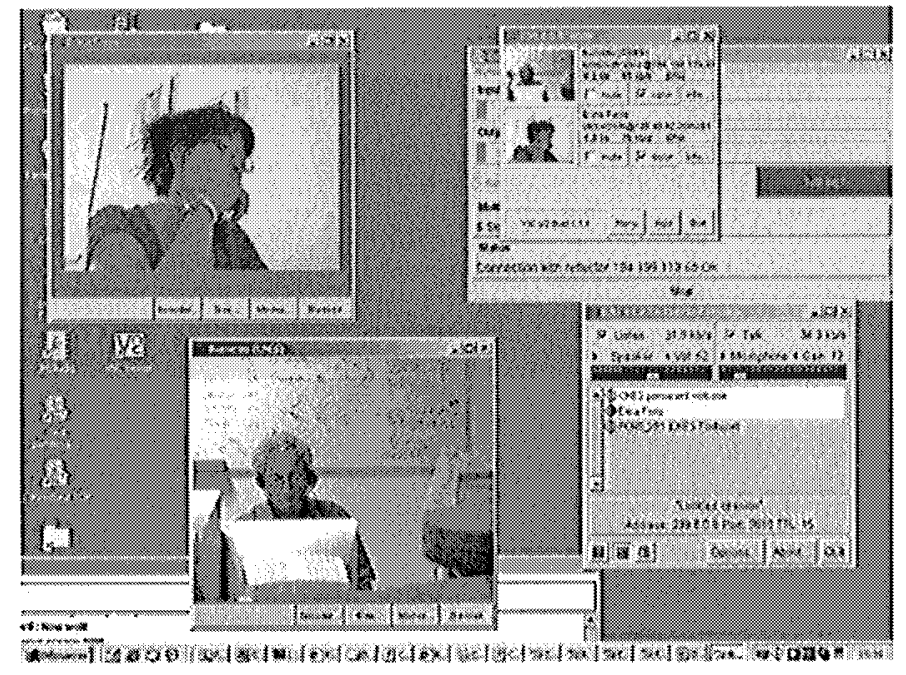

Figure 3: COST272 members working remotely 